\title{
ĐÁNH GIÁ MỐI TƯƠNG QUAN CỦA CÁC YẾU TỐ NGUY CƠ TIM MẠCH VỚI THANG ĐIỂM CHA2DS2-VASc Ở BỆNH NHÂN ĐỘT QUỴ CÓ RUNG NHĨ KHÔNG DO BÊNH VAN TIM \\ Lê Gia Hoàng ${ }^{1}$, Hồ Anh Bình ${ }^{2}$, Trần Thù̀a Nguyên ${ }^{2}$

\author{
1. BVĐK Tỉnh Khánh Hoà, 2. BV Trung ương Huế
}

DOI: $10.47122 / v j d e .2020 .45 .8$

\section{TÓM TẮT}

Đặt vấn đề: Điểm $\mathrm{CHA}_{2} \mathrm{DS}_{2}$-VASc càng cao thì nguy cơ đột quỵ càng gia tăng. Tuy vậy, trong thực hành lâm sàng hàng ngày có một tỷ lệ không nhỏ bệnh nhân đột quỵ do rung nhĩ nhưng lại có điểm $\mathrm{CHA}_{2} \mathrm{DS}_{2}$-VASc $=0$ và 1 , thuộc nhóm nguy cơ thấp đến trung bình. Muc tiêu: Đánh giá mối tương quan của các yếu tố nguy cơ tim mạch với thang điểm CHA2DS2VASC ở bệnh nhân đột quỵ có rung nhĩ không do bệnh van tim. Phương pháp và đối tự̛ng nghiên cứu: Nghiên cứu mô tả cắt ngang trên 91 bệnh nhân (BN) được chẩn đoán đột quỵ có rung nhĩ không do bệnh lý van tim. Kết quảa: Phối hợp 1 YTNC chiếm 13,2\%, trong đó bệnh mạch máu chiếm 7,7\%. Phối hợp 2 YTNC (40,7\%), trong đó tăng huyết áp + bệnh mạch máu chiếm 28,6\%. Phối hợp 3 YTNC (26,4\%), trong đó Suy tim +THA+ bệnh MM chiếm 14,3\%. Phối hợp 4 YTNC (18,7\%), trong đó Suy tim +THA+ đột quỵ và bệnh mạch máu chiếm $11,0 \%$. Đa số các nhóm YTNC có điểm $\mathrm{CHA}_{2} \mathrm{DS}_{2}-\mathrm{VASc} \geq 6$ chiếm tỷ lệ cao hơn 2 nhóm điểm $\mathrm{CHA}_{2} \mathrm{DS}_{2}-\mathrm{VASc}=2$ 3 điểm và $\mathrm{CHA}_{2} \mathrm{DS}_{2}-\mathrm{VASc} 4-5$ điểm. Điểm $\mathrm{CHA}_{2} \mathrm{DS}_{2}$-VASC trung bình tăng dần theo số các YTNC và $\mathrm{CHA}_{2} \mathrm{DS}_{2}-\mathrm{VASc}$ tương quan thuận với tuổi với phương trình hồi quy tuyến tính $\mathrm{y}=$ $0,084 \mathrm{x}-1,662$ và hệ số tương quan là $\mathrm{r}=0,485$. Kết luận: Số YTNC tương quan tỷ lệ thuận với điểm số $\mathrm{CHA}_{2} \mathrm{DS}_{2}-\mathrm{VASc}$.

Tù khóa: điểm số $C H A_{2} D S_{2}-V A S c$, đột quỵ

ABSTRACT
To evaluate the correlation of cardiac risk
factors with CHA2DS2-VASc score in stroke
patients with non-valvular atrial fibrillation
Lê Gia Hoàng ${ }^{1}$, Hồ Anh Bình ${ }^{2}$
Tran Thua Nguyen ${ }^{2}$

1. Khanh Hoa General Hospital

2. Hue Central Hospital

Background: The higher the CHA2DS2VASc score is, the higher the stroke risk is. However, in daily clinical practice there is a significant proportion of stroke patients with atrial fibrillation who present CHA2DS2-VASc $=0$ and 1 , which belong to the low to moderate risk group. Objectives: To evaluate the correlation of cardiac risk factors with CHA2DS2-VASC score in stroke patients with non-valvular atrial fibrillation. Method: Descriptive cross-sectional study on 91 patients are diagnosed stroke with non-valvular atrial fibrillation. Results: The combination of a risk factor accounted for $13.2 \%$, in which vascular diseases presented $7.7 \%$. The combination of 2 risk factors made up $40.7 \%$, in which hypertension, vascular disease accounted for $28.6 \%$. The combination of 3 risk factors constituted $26.4 \%$, in which heart failure, hypertension and vascular disease accounted for $14.3 \%$. The combination of 4 risk factors made up $18.7 \%$, in which heart failure, hypertension, stroke and vascular disease accounted for $11.0 \%$. The majority of the groups of risk factors with CHA2DS2-VASc score $\geq 6$ accounted for a higher percentage than that of two groups including CHA2DS2-VASc $=2-3$ and CHA2DS2-VASc 4-5. The mean CHA2DS2-VASC score increased with the number of risk factors and CHA2DS2-VASc score is positively correlated with age with the linear regression equation $\mathrm{y}=0.084 \mathrm{x}-1.662$ with the correlation coefficient $\mathrm{r}=0,485$. Conclusion: Number of risk factors correlated positively with CHA2DS2-VASc scores.

Key words: CHA2DS2-VASC score, stroke

Chịu trách nhiệm chính: Hồ Anh Bình

Ngày nhận bài: 29/10/2020 
Ngày phản biện khoa học: 04/12/2020

Ngày duyệt bài: 5/3/2021

Email: drhoanhbinh@gmail.com

Điện thoại: 0913489896

\section{1. ĐĂT VẤN ĐỀ}

Đối với rung nhĩ không do bệnh van tim, chiến lược dự phòng huyết khối dựa trên hệ thống phân tầng nguy cơ đột quy bằng thang điểm $\mathrm{CHA}_{2} \mathrm{DS}_{2}$-VASc và thuốc được chỉ định có thêm các kháng đông đường uống [17]. Điểm $\mathrm{CHA}_{2} \mathrm{DS}_{2}$-VASc càng cao thì nguy cơ đột quỵ càng gia tăng.

Tuy vậy, trong thực hành lâm sàng hàng ngày có một tỷ lệ không nhỏ bệnh nhân đột quy do rung nhĩ nhưng lại có điểm $\mathrm{CHA}_{2} \mathrm{DS}_{2}$-VASc $=0$ và 1 , thuộc nhóm nguy cơ thấp đến trung bình. Cũng như YTNC nào hoặc nhóm YTNC nào thường gặp trên bệnh nhân đột quỵ.

Xuất phát từ thực tiễn lâm sàng đó, cùng với mong muốn bên cạnh việc khảo sát các đặc điểm chung của bệnh nhân đột quỵ nhồi máu não có rung nhĩ không do bệnh van tim cùng với các YTNC, chúng tôi tiến hành nghiên cứu đề tài này với mục tiêu: Đánh giá mối tương quan của các yếu tố nguy co tim mạch với thang điểm CHA2DS2-VASC ở bệnh nhân đột quy có rung nhĩ không do bệnh van tim.

\section{2. ĐỐI TƯợNG VÀ PHƯƠNG PHÁP NGHIÊN CỨU}

\section{1. Đối tượng nghiên cứu}

\subsubsection{Tiêu chuẩn chọn bệnh nhân nghiên cứu}

Bệnh nhân phải được chẩn đoán đột quỵ có rung nhĩ không do bệnh lý van tim [4], [5]

+ Tiêu chuẩn chẩn đoán rung nhĩ [4]

+ Tiêu chuẩn chẩn đoán đột quỵ thiếu máu cục bộ [5]

\subsubsection{Tiêu chuẩn loại trù̀ bệnh nhân nghiên cứu}

- Bệnh nhân không đồng ý tham gia nghiên cứu.

- Bệnh nhân đột quỵ chảy máu não.

- Bệnh nhân đột quỵ nhồi máu não do u hoặc chấn thương.

- Bệnh nhân có bệnh lý van tim có/không rung nhĩ

2.1.3. Thời gian và địa điểm nghiên cứu

Bệnh nhân đột quỵ có rung nhĩ nhập viện vào khoa nội tim mạch của bệnh viện đa khoa tỉnh Khánh Hoà

Thời gian từ tháng 4.2019 đến tháng 4. 2020.

\subsection{Phương pháp nghiên cứu}

\subsubsection{Thiết kế nghiên cúu}

Phương pháp nghiên cứu cắt ngang mô tả

\subsubsection{Các bước tiến hành}

- Thu nhập phần hành chính:

- Khai thác về tiền sử và bệnh sử:

- Thang điểm đánh giá nguy cơ đột quỵ do huyết khối ở các bệnh nhân rung nhĩ không do bệnh van tim CHA2DS2-VASc [11]

\begin{tabular}{|c|c|c|}
\hline \multicolumn{2}{|c|}{ Yếu tố nguy cơ lâm sàng } & CHA2DS2-VASc \\
\hline Suy tim sung huyết & (Congestive Heart Failure) & 1 \\
\hline Tăng huyết áp & (Hypertension) & 1 \\
\hline Tuổi trên 75 & ( $\underline{\text { Age })}$ & 2 \\
\hline
\end{tabular}




\begin{tabular}{|c|c|c|}
\hline Đái tháo đường & (Diabetes Mellitus) & 1 \\
\hline Tiền sử đột quỵ & (Stroke) & 2 \\
\hline Bệnh mạch máu & (Vascular disease) & 1 \\
\hline Tuổi từ 65 đến 74 & ( & 1 \\
\hline Giới nữ & $(\underline{\operatorname{Sex}})$ & 1 \\
\hline \multicolumn{2}{|r|}{ Tổng } & 9 \\
\hline
\end{tabular}

- Không có nguy cơ ( $\left.\mathrm{CHA}_{2} \mathrm{DS}_{2}-\mathrm{VASC}=0\right)$

- Nguy cơ trung bình $\left(\mathrm{CHA}_{2} \mathrm{DS}_{2}\right.$-VASC $\left.=1-2\right)$

- Nguy cơ cao $\left(\mathrm{CHA}_{2} \mathrm{DS}_{2}\right.$-VASC $\left.>2\right)$

2.2.3. Phương pháp xử lý số liệu: Việc nhập và xử lý số liệu được thực hiện trên máy vi tính theo chương trình Excel 2010, SPSS 22.0.

3. KÊTT QUẢ NGHIÊN CÚU

3.1. Các yếu tố nguy cơ phối hợp

Bảng 3.1. Tỷ lệ các YTNC phối hợp

\begin{tabular}{|c|c|c|c|c|c|}
\hline \multirow{2}{*}{$\begin{array}{c}\text { Số } \\
\text { YTNC }\end{array}$} & \multirow{2}{*}{ Loại YTNC phối họ̣p } & \multirow{2}{*}{$\mathbf{n}$} & \multirow{2}{*}{ Tỷ lệ \% } & \multicolumn{2}{|c|}{ Tổng số } \\
\hline & & & & $\mathbf{n}$ & $\%$ \\
\hline \multirow{3}{*}{1} & THA & 3 & 3,3 & \multirow{3}{*}{12} & \multirow{3}{*}{13,2} \\
\hline & Đột Quỵ (ĐQ) & 2 & 2,2 & & \\
\hline & Bệnh MM & 7 & 7,7 & & \\
\hline \multirow{7}{*}{2} & $\mathrm{ST}+\mathrm{THA}$ & 1 & 1,1 & \multirow{7}{*}{37} & \multirow{7}{*}{40,7} \\
\hline & $\mathrm{ST}+\mathrm{DQ}$ & 1 & 1,1 & & \\
\hline & $\mathrm{THA}+\mathrm{DQ}$ & 1 & 1,1 & & \\
\hline & ĐTĐ + bệnh MM & 1 & 1,1 & & \\
\hline & ĐQ+ bệnh MM & 1 & 1,1 & & \\
\hline & ST+ bệnh MM & 6 & 6,6 & & \\
\hline & THA + bệnh MM & 26 & 28,6 & & \\
\hline \multirow{5}{*}{3} & $\mathrm{ST}+\mathrm{THA}+$ ĐTÐ & 1 & 1,1 & \multirow{5}{*}{24} & \multirow{5}{*}{26,4} \\
\hline & THA +ĐTĐ + bệnh MM & 2 & 2,2 & & \\
\hline & ST + ĐQ + bệnh MM & 3 & 3,3 & & \\
\hline & THA + ĐQ + bệnh MM & 5 & 5,5 & & \\
\hline & ST + THA + bệnh MM & 13 & 14,3 & & \\
\hline \multirow{4}{*}{4} & THA + ĐTĐ + ĐQ + bệnh MM & 1 & 1,1 & \multirow{4}{*}{17} & \multirow{4}{*}{18,7} \\
\hline & ST+ ĐTĐ + ĐQ + bệnh MM & 1 & 1,1 & & \\
\hline & ST+ THA + ĐTĐ + bệnh MM & 5 & 5,5 & & \\
\hline & ST+ THA + ĐQ + bệnh MM & 10 & 11,0 & & \\
\hline \multicolumn{2}{|c|}{ Không có yêu tố nguy cơ } & 1 & 1,1 & 1,1 & 1,1 \\
\hline & Tổng số & 91 & 100,0 & 91 & 100 \\
\hline
\end{tabular}




\section{Nhận xét:}

- Có 1 YTNC chiếm 13,2\%, trong đó bệnh MM chiếm 7,7\%

- Có 2 YTNC phối hợp chiếm 40,7\%, trong đó tăng huyết áp + bệnh MM chiếm 28,6\%.

- Có 3 YTNC phối hợp chiếm 26,4\%, trong đó Suy tim +THA+ bệnh MM chiếm 14,3\%.

- Có 4 YTNC phối hợp chiếm 18,7\%, trong đó Suy tim +THA+ đột quỵ và bệnh MM chiếm $11,0 \%$.

3.2. Liên quan giữa YTNC theo điểm $\mathrm{CHA}_{2} \mathrm{DS}_{2}$-VASC

Bảng 3.2. Liên quan giữa YTNC theo điểm $\mathrm{CHA}_{2} \mathrm{DS}_{2}-\mathrm{VASC}$

\begin{tabular}{|c|c|c|c|c|c|c|c|c|}
\hline \multirow{2}{*}{$\begin{array}{c}\text { Điểm } \\
\text { CHA }_{2} \text { DS }_{2-}- \\
\text { VASC }\end{array}$} & \multicolumn{2}{|c|}{$\begin{array}{c}2-3 \text { diểm } \\
(n=17)\end{array}$} & \multicolumn{2}{|c|}{$\begin{array}{c}\text { 4-5 điểm } \\
(n=46)\end{array}$} & \multicolumn{2}{|c|}{$\begin{array}{c}\geq 6 \text { điểm } \\
(n=28)\end{array}$} & \multirow{2}{*}{$\begin{array}{c}\text { Tổng } \\
(n=91)\end{array}$} & \multirow{2}{*}{$\mathbf{p}$} \\
\hline & $\mathrm{N}$ & $\%$ & $\mathrm{n}$ & $\%$ & $\mathrm{n}$ & $\%$ & & \\
\hline THA & 10 & 14,7 & 34 & 50,0 & 24 & 35,3 & 68 & $>0,05$ \\
\hline Suy tim & 4 & 9,8 & 15 & 36,5 & 22 & 53,7 & 41 & $<0,01$ \\
\hline ĐТÐ & 2 & 18,2 & 2 & 18,2 & 7 & 63,6 & 11 & $<0,05$ \\
\hline Tiền sử ĐQ & 1 & 4,0 & 5 & 20,0 & 19 & 76,0 & 25 & $<0,01$ \\
\hline Bệnh MM & 12 & 14,8 & 42 & 51,9 & 27 & 33,3 & 81 & $>0,05$ \\
\hline$\geq 75$ tuổi & 0 & 0 & 36 & 64,4 & 20 & 35,7 & 56 & $<0,01$ \\
\hline
\end{tabular}

Nhận xét: Đa số các nhóm YTNC có điểm $\mathrm{CHA}_{2} \mathrm{DS}_{2}-\mathrm{VASc} \geq 6$ chiếm tỷ lệ cao hơn 2 nhóm điểm $\mathrm{CHA}_{2} \mathrm{DS}_{2}$-VASc còn lại:

- THA ở điểm $\mathrm{CHA}_{2} \mathrm{DS}_{2}$-VASc là 4-5 có tỷ lệ 50,0\%

- Suy tim ở điểm $\mathrm{CHA}_{2} \mathrm{DS}_{2}$-VASc $\geq 6$ có tỷ lệ $53,7 \%$

- ĐTĐ điểm $\mathrm{CHA}_{2} \mathrm{DS}_{2}-\mathrm{VASc} \geq 6$ có tỷ lệ $63,6 \%$

- Tiền sử ĐQ điểm $\mathrm{CHA}_{2} \mathrm{DS}_{2}-\mathrm{VASc} \geq 6$ có tỷ lệ $76,0 \%$

- Bệnh mạch máu điểm $\mathrm{CHA}_{2} \mathrm{DS}_{2}$-VASc $=4-5$ có tỷ lệ $51,9 \%$

3.3. Liên quan số nhóm YTNC và thang điểm $\mathrm{CHA}_{2} \mathrm{DS}_{2}-\mathrm{VASC}$

Bảng 3.3. Liên quan số nhóm YTNC và thang điểm $\mathrm{CHA}_{2} \mathrm{DS}_{2}-\mathrm{VASC}$

\begin{tabular}{|c|c|c|c|}
\hline Số nhóm YTNC & $\mathbf{n}$ & $\mathbf{C H A}_{\mathbf{2}} \mathbf{D S}_{2}$-VASC & p \\
\hline Không có YTNC & 1 & $2,00 \pm 0,00$ & \\
\hline 1 YTNC & 12 & $3,58 \pm 1,24$ & \multirow{2}{*}{$<0,01$} \\
\hline 2 YTNC & 37 & $3,97 \pm 1,01$ & \\
\hline 3YTNC & 24 & $5,33 \pm 1,05$ & \\
\hline 4 YTNC & 17 & $6,88 \pm 0,69$ & \\
\hline Tổng & 91 & $4,80 \pm 1,56$ & \\
\hline
\end{tabular}

Nhận xét: Điểm $\mathrm{CHA}_{2} \mathrm{DS}_{2}$-VASC trung bình tăng dần theo số các YTNC

3.4. Tương quan giữa $\mathrm{CHA}_{2} \mathrm{DS}_{2}-\mathrm{VASC}$ và các thông số lipid máu, huyết áp và tuổi

Bảng 3.4. Hệ số tương quan giữa $\mathrm{CHA}_{2} \mathrm{DS}_{2}-\mathrm{VASC}$ và các thông số

\begin{tabular}{|c|c|c|c|c|c|c|c|}
\hline $\begin{array}{c}\text { CHA }_{2} \text { DS }_{2} \\
\text {-VASC }\end{array}$ & CHO & TRI & HDL_c & LDL_c & HATT & HATTr & Tuổi \\
\hline $\mathrm{R}$ & -0.184 & -0.163 & -0.010 & -0.198 & 0.042 & 0.021 & $\mathbf{0 , 4 8 5}$ \\
\hline $\mathrm{P}$ & 0.094 & 0.137 & 0.930 & 0.072 & 0.693 & 0.844 & 0.000 \\
\hline $\mathrm{N}$ & 84 & 84 & 84 & 84 & 91 & 91 & 91 \\
\hline
\end{tabular}


Nhận xét: $\mathrm{CHA}_{2} \mathrm{DS}_{2}$-VASC không có tương quan với biland lipid, HATT, HATTr, chỉ có tương quan với tuổi.

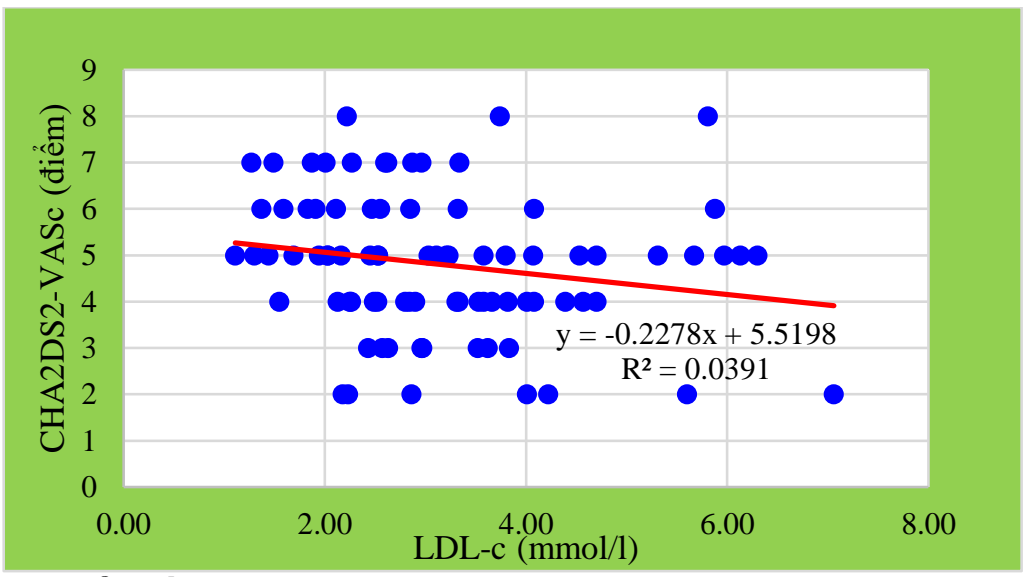

Biểu đồ 3.1. Tương quan giữa $\mathrm{CHA}_{2} \mathrm{DS}_{2}-\mathrm{VASC}$ và $\mathrm{LDL}-\mathrm{c}$ Nhận xét: $\mathrm{CHA}_{2} \mathrm{DS}_{2}$-VASc không tương quan với LDL-c

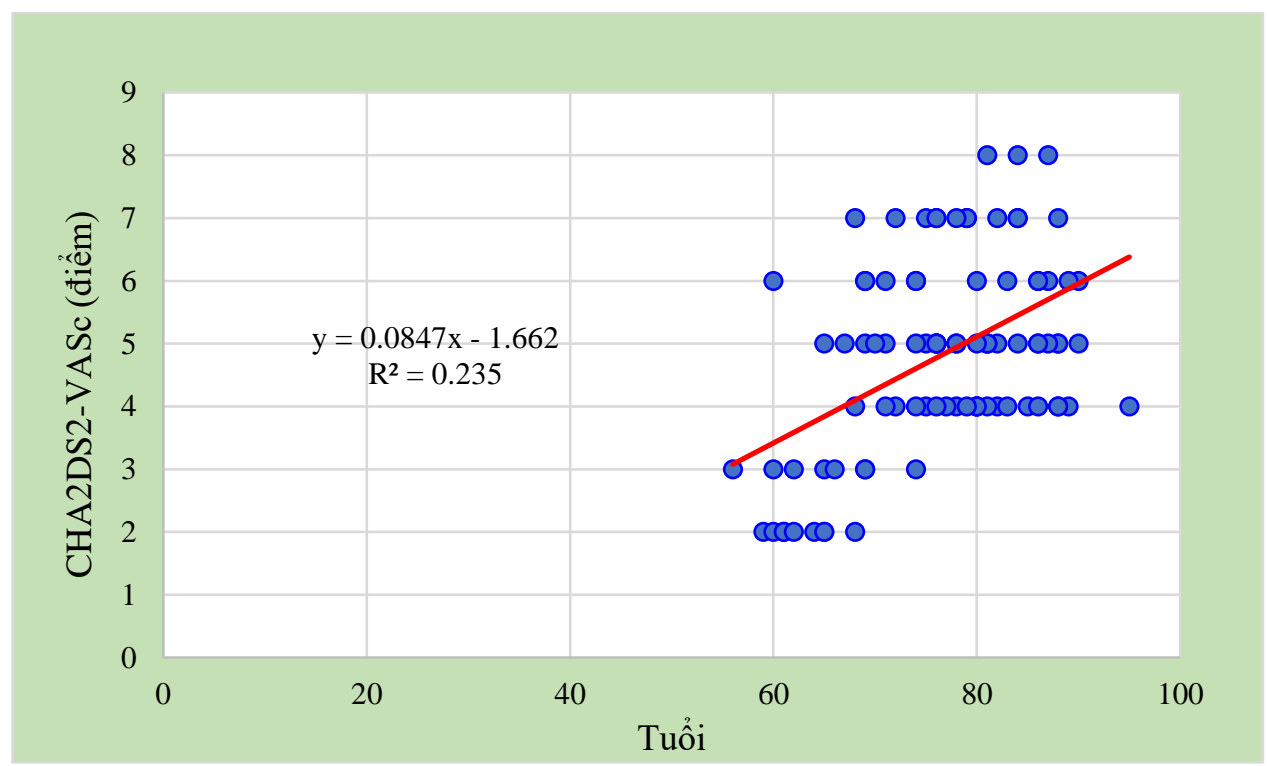

Biểu đồ 3.2. Tương quan giữa tuổi và $\mathrm{CHA}_{2} \mathrm{DS}_{2}$-VASC

Nhận xét: $\mathrm{CHA}_{2} \mathrm{DS}_{2}-\mathrm{VASc}$ tương quan thuận với tuổi và phương trình hồi quy tuyến tính $\mathrm{y}=$ $0,084 \mathrm{x}-1,662$ và hệ số tương quan là $\mathrm{r}=0,485$.

\section{BÀN LUẬN \\ 4.1. Các YTNC phối hợp trên cùng 1 bệnh nhân \\ Nhóm 1 YTNC chiếm 13,2\%, trong đó bệnh mạch máu là $7,7 \%$; nhóm 2 YTNC là $40,7 \%$ trong đó nhóm $\mathrm{BN}$ có THA và bệnh mạch máu chiếm 28,6\%; nhóm 3 YTNC}

chiếm $26,4 \%$ trong đó có $13 \mathrm{BN}$ vừa suy tim vừa $\mathrm{THA}$, vừa bệnh mạch máu chiếm $14,3 \%$; nhóm 4 YTNC chiếm 18,7\% trong đó $10 \mathrm{BN}$ có 4 YTNC phối hợp là suy tim, THA, đột quy. và bệnh mạch máu chiếm $11,0 \%$.

Đái tháo đường và tăng huyết áp là hai bệnh phổ biến đồng thời là YTNC độc lập hàng đầu 
của bệnh tim mạch, bệnh thận và vữa xơ động mạch. Sinh bệnh học của bệnh tăng huyết áp ở bệnh nhân đái tháo đường típ 1 và 2 là khác nhau. Trong mọi trường hợp, tăng huyết áp làm nặng tiến triển của bệnh nhân đột quỵ não và làm tăng nguy cơ của cả hai biến chứng mạch máu lớn và mạch máu nhỏ [9]. Nghiên cứu của Nguyễn Thế Anh (2018) ghi nhận tỷ lệ tăng huyết áp ở bệnh nhân nhồi máu não có đái tháo đường cao hơn so với bệnh nhân nhồi máu não không đái tháo đường [1].

Chương trình nghiên cứu tim mạch Honolulu ở những người đàn ông Nhật sống ở Hawaii cho thấy mức độ kém dung nạp glucose tăng lên đồng nghĩa với việc tăng nguy cơ đột quỵ do huyêt khối gấp đôi. Đối với nhồi máu não, ảnh hưởng của đái tháo đường ở bệnh nhân nữ nhiều hơn nam. Bệnh nhân đái tháo đường thường có tập hợp nhiều YTNC như tăng huyết áp, béo bụng, rối loạn lipid máu và kháng insulin. Vì vậy việc theo dõi và điều trị đái tháo đường kết hợp với việc kiểm soát các YTNC kèm theo sẽ làm giảm nguy cơ đột quy. [18].

\subsection{Liên quan giữa các YTNC với điểm $\mathrm{CHA}_{2} \mathrm{DS}_{2}$-VASC}

Kết quả chúng tôi theo phân chia nhóm phân điểm của Hong H.J. [12]và cộng sự (2012) với điểm $\mathrm{CHA}_{2} \mathrm{DS}_{2}-\mathrm{VASc}$ được chia thành bốn nhóm.

Với bệnh nhân THA, điểm $\mathrm{CHA}_{2} \mathrm{DS}_{2}$ VASc $4-5$ có tỷ lệ $50,0 \%(\mathrm{p}>0,05)$; suy tim ở điểm $\mathrm{CHA}_{2} \mathrm{DS}_{2}$-VASc $\geq 6$ có tỷ lệ $53,7 \%$ $(\mathrm{p}<0,01)$, ĐTÐ điểm $\mathrm{CHA}_{2} \mathrm{DS}_{2}$-VASc $\geq 6$ có tỷ lệ $63,6 \%(\mathrm{p}<0,05)$; Tiền sử đột quỵ điểm $\mathrm{CHA}_{2} \mathrm{DS}_{2}$-VASc $\geq 6$ có tỷ lệ $76,0 \%(\mathrm{p}<0,01)$ và bệnh mạch máu điểm $\mathrm{CHA}_{2} \mathrm{DS}_{2}$-VASc $=4$ 5 có tỷ lệ $51,9 \%$ nhưng sự khác biệt không có ý nghĩa thống kê $(\mathrm{p}>0,05)$. Nhóm $\geq 75$ tuổi chiếm $64,4 \%$ ở phân nhóm 4-5 điểm.

Kết quả chúng tôi ghi nhận có tỷ lệ bệnh mạch máu cao nhất là $89 \%$, so với các tác giả Nguyễn Thị Bảo Liên (2018), bệnh mạch máu (12,3\%) [7]. Đinh Hữu Hùng (2014) bệnh mạch máu nhỏ $(35,3 \%)$ [6]. Khan N.A và cs (2017) nghiên cứu 3 vùng về bệnh tim mạch ở bệnh nhân đột quỵ ghi nhận tại Trung quốc là 13,7\%; người da trắng $(10,3 \%)$ và Nam Á $(11,0 \%)$ [54]. Đỗ Minh Chi (2015) ghi nhận bệnh mạch vành là $28,6 \%$, bệnh van tim $(22,4 \%)$ [2]

Theo Go As (2014), Hiệp hội tim mạch học Hoa Kỳ (AHA) cho rằng bệnh lý mạch máu là nguyên nhân hàng đầu của tử vong toàn cầu, làm tăng nguy cơ biến cố mạch máu ở bệnh nhân có tiền sử đột quy- cơn thiếu máu não thoáng qua, đặc biệt nguy cơ dài hạn về biến cố động mạch vành [16]. Có 3 nhóm mạch máu quan trọng là động mạch vành, động mạch não và động mạch ngoại biên, mặc dù nguy cơ cao bị bệnh lý động mạch ngoại biên ở bệnh nhân bị đột quỵ và nguy cơ đột quỵ ở bệnh nhân bị bệnh lý động mạch ngoại biên việc xử trí bệnh lý động mạch ngoại biên thường bị bỏ qua trong quá trình điều trị, phòng ngừa và hồi phục.

4.3. Liên quan giữa các YTNC với thang điểm CHA $\mathrm{DS}_{2}$-VASC

Điểm $\mathrm{CHA}_{2} \mathrm{DS}_{2}$-VASc trung bình tăng dần theo số các YTNC, trong đó 12 bệnh nhân có 1 YTNC có điểm $\mathrm{CHA}_{2} \mathrm{DS}_{2}$-VASc trung bình là 3,58 $\pm 1,2$ điểm, 37 bệnh nhân có 2 YTNC với điểm $\mathrm{CHA}_{2} \mathrm{DS}_{2}$-VASc trung bình là $3,97 \pm$ 1,01 điểm; 24 bệnh nhân có 3 YTNC với điểm $\mathrm{CHA}_{2} \mathrm{DS}_{2}$-VASc trung bình là $5,33 \pm 1,05$ điểm và $17 \mathrm{BN}$ có $4 \mathrm{YTNC}$ với điểm $\mathrm{CHA}_{2} \mathrm{DS}_{2}$-VASc trung bình là $6,88 \pm 0,69$ điểm (bảng 3.3).

Qua bảng 3.4 cho thấy điểm $\mathrm{CHA}_{2} \mathrm{DS}_{2-}$ VASc không có tương quan với HATT, HATTr và nhóm bilan lipid. Tuổi tương quan thuận với $\mathrm{CHA}_{2} \mathrm{DS}_{2}-\mathrm{VASc}$ với phương trình hồi quy tuyến tính $\mathrm{y}=0,084 \mathrm{x}-1,662$ và hệ số tương quan là $\mathrm{r}=0,485$.

Điểm CHADS 2 hoặc $\mathrm{CHA}_{2} \mathrm{DS}_{2}$-VASc cao hơn có liên quan với tăng nguy cơ đột quỵ thiếu máu cục bộ ở bệnh nhân rung nhĩ không do bệnh van tim [4]. Tuy nhiên, không có số liệu đề cập về thương tổn thần kinh khu trú sớm sau khi đột quỵ theo mức độ nguy cơ.

Kết quả của Ngô Văn Đàn (2016) ghi nhận điểm $\mathrm{CHA}_{2} \mathrm{DS}_{2}$-VASc $=4$ có tỷ lệ cao nhất $33,8 \%$. Điểm $\mathrm{CHA}_{2} \mathrm{DS}_{2}-\mathrm{VASc}=5$ là $21,8 \%$; thấp nhất $\mathrm{CHA}_{2} \mathrm{DS}_{2}$-VASC là điểm 8 chỉ chiếm 1,3\% [3]. Nghiên cứu của Bùi Thúc 
Quang (2013) cho thấy phân bố khá đều ở các nhóm: 1 điểm chiếm $24,8 \%$; 2 điểm là $17,9 \% ; 3$ điểm là $19,7 \%$ và ít hơn ở nhóm 6 điểm $5,1 \%, 7$ điểm $(4,3 \%)$, không có $\mathrm{CHA}_{2} \mathrm{DS}_{2}$-VASc 8 điểm [8].

\subsection{Tương quan giữa $\mathrm{CHA}_{2} \mathrm{DS}_{2}$-VASC} và các thông số lipid máu, huyết áp và tuổi

Rối loạn chuyển hóa lipid là một trong những yếu tố khởi đầu cho quá trình hình thành và phát triển của xơ vữa động mạch. Thực ra các tổn thương xơ vữa động mạch xuất hiện rất sớm nhưng chỉ biểu hiện trên lâm sàng ở lứa tuổi 50-60 tuổi (biểu hiện trên xét nghiệm là các rối loạn chuyển hóa lipid máu). Xơ vữa động mạch là bệnh rất phổ biến ở người cao tuổi, tuổi càng cao càng hay bị xơ vữa động mạch. Trong nghiên cứu của chúng tôi rối loạn chuyển hóa lipid chiếm $66,7 \%$ (tăng cholesterol toàn phần chiếm $36,9 \%$, kế đó tăng triglycerid (16,7\%), tăng LDLc $(35,7 \%)$, giảm HDLc $(34,5 \%)$. Mặc dù rối loạn chuyển hóa lipid của chúng tôi và các tác giả không hoàn toàn giống nhau nhưng đều nhận thấy loại tổn thương này chiếm một tỷ lệ cao ở các bệnh nhân đột quỵ. Tỷ lệ $66,7 \%$ bệnh nhân bị rối loạn lipid máu trong nghiên cứu của chúng tôi cho thấy cần phải khảo sát thêm lại toàn bộ chương trình dự phòng rối loạn lipid máu, phổ biến kiến thức trong cộng đồng nhằm chẩn đoán sớm các rối loạn lipid, hướng dẫn chế độ ăn, chế độ luyện tập và điều trị bằng thuốc khi có chỉ định để hạn chế tối đa tình trạng tăng lipid máu, một trong những nguyên nhân dẫn đến xơ vữa động mạch và đột quỵ.

Lý do của sự khác biệt trong các nghiên cứu có thể do điểm giới hạn xác định mức bất thường về các biến số lipid máu khác nhau. Những nghiên cứu gần đây khi tách riêng các phân nhóm đột quỵ đã ghi nhận: tăng LDLc và giảm HDLc là YTNC cho đột quỵ thiếu máu não. Tần suất đột quỵ cũng cao hơn bình thường ở nhóm người có tăng lipid máu.

Tồ chức y tế thế giới cũng đã khuyến cáo hai loại bất thường của lipid máu có nguy cơ gây xơ vữa động mạch cao là tăng triglycerid kêt hợp với tăng cholesterol toàn phần [20].

Nghiên cứu của Khan N.A. và cs (2017) đánh giá nguy cơ đột quỵ ở các quần thể dân số khác nhau dựa trên cỡ mẫu lớn cho kết quả: 3.290 người Nam Á, 4.444 người Trung Quốc, và 160.944 người da trắng có đột quỵ thiếu máu não cục bộ (cơ sở dữ liệu về điều tra dân số và hành chính từ năm 1997 đến năm 2000). Kết quả nghiên cứu cũng cho thấy người dân ở khu vực Nam Á có tuổi khởi phát đột quỵ thấp hơn người da trắng (70 tuổi so với 74 tuổi). Tỷ lệ mắc đột quỵ trong năm 2010 của người dân Nam Á thấp hơn $63 \%$ và Trung Quốc là $43 \%$ so với người da trắng [13]. Như vậy, khi so sánh với các tác giả nước ngoài, chúng tôi cũng nhận thấy tuổi trung bình của các bệnh nhân đột quỵ nhồi máu não cũng có sự tương đồng nhất định, mặc dù nhóm tuổi được phân chia rõ rệt hơn trong đánh giá của các nghiên cứu trên thế giới. Bên cạnh đó, sự khác biệt giữa các nước, đối tượng đích của nghiên cứu cũng như chất lượng chăm sóc sức khỏe của các quốc gia cũng là một trong những yếu tố gây nên sự khác biệt về tuổi tác. Bên cạnh đó, yếu tố tầm soát và tuân thủ việc sàng lọc cộng đồng cũng là một trong những nguyên nhân gia tăng sự cách biệt, đặc biệt là về phân bố nhóm tuổi xuất hiện đột quỵ giữa các nghiên cứu.

Những nghiên cứu khảo sát trên nhóm đối tượng trẻ tuổi cho kết quả khác biệt: Tại Phần Lan, Putuala J. (2009) tuổi thường gặp là 15 đến 49 tuổi, trong đó tần suất đột quỵ tăng mạnh ở tuổi 40 (mẫu nghiên cứu là 1.008 đối tượng đột quỵ) tuổi TB là 41,3 \pm 7,6 tuổi [15], kết quả này khá phù hợp với nghiên cứu của Morikawa Y. tại Nhật Bản [14] .Tuy nhiên, nghiên cứu Van Alebeek (2017) lại cho thấy, tuổi đột quỵ ở người trẻ thường dao động trong khoảng từ 18 đến 50 tuổi, tuổi $\mathrm{TB}$ ghi nhận là 40,7 $\pm 7,7$ tuổi [ 19].

Trước đây đột quỵ não thường xảy ra ở những người cao tuồi, nhưng ngày nay có khoảng $25 \%$ ca đột quỵ lại xảy ra ở những người trẻ tuổi. Đột quỵ ở người trẻ đang có chiều hướng gia tăng đáng báo động và thường gặp ở những người lạm dụng bia, rượu, thuốc lá, sử dụng các chất kích thích [10].

\section{KẾT LUẬN}

- 1 YTNC chiếm 13,2\%, trong đó bệnh mạch máu chiếm $7,7 \%$. 
- Phối hợp 2 YTNC (40,7\%), trong đó tăng huyết áp + bệnh mạch máu chiếm $28,6 \%$.

- Phối hợp 3 YTNC (26,4\%), trong đó Suy tim +THA+ bệnh mạch máu chiếm 14,3\%.

- Phối hợp 4 YTNC (18,7\%), trong đó Suy tim + THA+ đột quỵ và bệnh mạch máu chiếm $11,0 \%$.

- Đa số các nhóm YTNC có điểm $\mathrm{CHA}_{2} \mathrm{DS}_{2}$-VASc $\geq 6$ chiếm tỷ lệ cao hơn 2 nhóm điểm $\mathrm{CHA}_{2} \mathrm{DS}_{2}-\mathrm{VASc}=2-3$ điểm và $\mathrm{CHA}_{2} \mathrm{DS}_{2}$-VASc 4-5 điểm.

- Điểm $\mathrm{CHA}_{2} \mathrm{DS}_{2}$-VASC trung bình tăng dần theo số các YTNC

$-\mathrm{CHA}_{2} \mathrm{DS}_{2}-\mathrm{VASc}$ tương quan thuận với tuổi với phương trình hồi quy tuyến tính $\mathrm{y}=$ $0,084 \mathrm{x}-1,662$ và hệ số tương quan là $\mathrm{r}=0,485$.

\section{TÀI LIỆU THAM KHẢO}

1. Nguyễn Thế Anh (2018), Nghiên cưu đặc điềm lâm sàng, cận lâm sàng của nhồi máu não ở người cao tuổi có bệnh đái tháo đương, Luận án tiến sĩ, Viện nghiên cứu Khoa học y Dược lâm sàng 108 ,

2. Đố Minh Chi, Cao Phi Phong (2015), Nghiên cứu các yếu tố tiên lượng trên bệnh nhân nhồi máu não có rung nhĩ, $Y$ học TP Hồ Chí Minh, 19(1), tr.240-245

3. Ngô Văn Đàn (2016), Phân tầng nguy cơ đột quỵ não theo thang điểm CHADS2 và CHA2DS2-VASc ở bệnh nhân tăng huyết áp có kèm theo rung nhĩ, Tạp chi Y-Dược hoc quân sụ (4), tr, 158-162

4. Hội tim mạch học Việt Nam (2016). Khuyến cáo về chẩn đoán và điều trị rung nhĩ

5. 5Hội tim mạch học Việt nam (2008). Khuyến cáo về chẩn đoán và điều trị trị nhồi máu não cấp (Đột quỵ thiếu máu não)

6. Đinh Hữu Hùng (2014), Nguy co tái phát sau đột quy thiếu máu não cuc bộ theo phân tầng một số yếu tố liên quan, LATS ĐH Y Dược TP Hồ Chí Minh

7. Nguyễn Thị Bảo Liên (2018), Đặc điểm lâm sàng, cận lâm sàng, các yếu tố nguy co đột quy của nhồi máu não cấp ở bệnh nhân rung nhĩ không do bệnh van tim, Luận án tiến sĩ ĐHY Hà Nội
8. Bùi Thúc Quang, Vũ Điện Biên, Phạm Nguyên Sơn (2013). Giá trị dự báo huyết khối tiểu nhĩ trái bằng thang điểm $\mathrm{ChaDS}_{2}$; $\mathrm{Cha}_{2} \mathrm{DS}_{2} \mathrm{VASc}$, các thông số siêu âm tim thành ngực ở bệnh nhân rung nhĩ không có bệnh van tim, Tạp chí Y dược $h o c$, Trường Đại học $\mathrm{Y}$ dược Huế, 11, tr 36-43.

9. American Diabetes Association (2017), Standards of Medical Care in Diabetes 2017, pp 1 - 33.

10. Aparicio H. J., Himali J. J., Satizabal C. L., Pase, M. P., et al. (2019). Temporal Trends in Ischemic Stroke Incidence in Younger Adults in the Framingham Study. Stroke, pp.1558-1560

11. Camm A. John; Kirchhof P, Gregory Y.H. Lip (2011), Guidelines for the management of atrial fibrillation, European Heart Journal

12. Hong, H. J., Kim, Y. D., Cha, M.-J., Kim, J., et al (2011). Early neurological outcomes according to CHADS2score in stroke patients with non-valvular atrial fibrillation. European Journal of Neurology, 19(2), 284-290.

13. Khan N. A., McAlister F. A., Pilote L., Palepu A., et al (2017). Temporal trends in stroke incidence in South Asian, Chinese and white patients: A population based analysis. PLOS ONE, 12(5), e0175556.

14. Morikawa Y., Nakagawa H., Naruse Y., Nishijo M., et al. (2000). Trends in Stroke Incidence and Acute Case Fatality in a Japanese Rural Area: The Oyabe Study. Stroke, 31(7), 1583-1587.

15. Putaala J., Metso, A. J., Metso T. M., Konkola N., Kraemer Y., et al (2009). Analysis of 1008 consecutive patients aged 15 to 49 with first-ever ischemic stroke: the helsinki young stroke registry. Stroke, 40(4), 1195-1203.

16. Rothwell P. M. (2000). Carotid Artery Disease and the Risk of Ischaemic Stroke and Coronary Vascular Events, Cerebrovascular Diseases, 10(5),21-33 
17. Torp-Pedersen C., Hansen, M., Lip, G., \& Olesen J. (2012). The value of the CHA2DS2-VASc score for refining stroke risk stratification in patients with atrial fibrillation with a CHADS2 score 0-1: A nationwide cohort study. Thrombosis and Haemostasis, 107(06), 1172-1179

18. Tun, N. N., Arunagirinathan, G., Munshi, S. K., et al (2017). Diabetes mellitus and stroke: A clinical update. World Journal of Diabetes, 8(6), 235.
19. Van Alebeek, M. E., Arntz, R. M., Ekker, M. S., Synhaeve, N. E., et al. (2017). Risk factors and mechanisms of stroke in young adults: The FUTURE study. Journal of Cerebral Blood Flow \& Metabolism, 38(9), p.1631-1641

20. World Health Organization (2011). Global status report on noncommunicable diseases 2010, 22-138. 